\title{
The Protestant ethic effect in a multichoice environment
}

\author{
RONALD M. STEPHENS \\ Auburn University, Auburn, Alabama 36830
}

and

\author{
LEROY P. METZE and JAMES R. CRAIG \\ Western Kentucky University, Bowling Green, Kentucky 42101
}

\begin{abstract}
The Protestant ethic effect was investigated using eight rats that learned to barpress for food in a four-choice situation involving: (1) a functional bar and food dish where a pellet was dispensed with each barpress, (2) a nonfunctional bar and food dish which contained no free food during training, (3) a nonfunctional bar, and (4) a foodcup which contained no free food during training. After a stable rate of responding was observed, free-food pellets were added, and the choice behavior of the animals was observed. The results indicated that the rats preferred to barpress to obtain food in the presence of other food-getting or manipulation activities.
\end{abstract}

The Protestant ethic effect refers to the observation that, under certain circumstances, an organism will prefer to "work" for a reinforcer rather than receive the same reinforcer "free." The pheonmenon has been displayed in a variety of situations using different reinforcement schedules (Carder \& Berkowitz, 1970; Jensen, 1963; Neuringer, 1970), types of reinforcers (Taylor, 1972), and organisms (Singh \& Query, 1971). Almost invariably, the subject is placed on deprivation and trained to respond (i.e., to "work") for some reinforcer. After a period of training, the subject is given a "choice" of either continuing to respond for the reinforcer or receiving the reinforcer "free" (i.e., response-independent reinforcement). For example, food pellets are placed within the test chamber so the organism may either "freely" partake of the food or produce the conditioned behavior to receive food.

Several explanations of the phenomenon have been offered. Jensen (1963) and Neuringer (1970) have attempted to account for this effect on the basis of the subject's strong habit strength of responding. Other explanations have focused on conditioning variables such as secondary reinforcement (Alferink, Crossman, \& Cheney, 1973) or amount of deprivation (Tarte \& Snyder, 1972). A previously advanced (Singh, 1970) explanation of this effect was based on an active model of animal behavior (White, 1959); that is, animals are motivated to actively manipulate their environment. The subject's general behavior is directed toward controlling and modifying the external world. Support for an environmental-manipulation conceptualization

Portions of the research were presented at the meeting of the Southeastern Psychological Association, Hollywood, Florida 1974. The paper is sponsored by $R$ obert $W$. Schaeffer, who takes full editorial responsibility for its contents. The editorial assistance and helpful comments of Michael Brush are gratefully acknowledged. Requests for reprints may be sent to Dr. Leroy $\mathrm{P}$. Metze, Department of Psychology, Western Kentucky University, Bowling Green, Kentucky 42101. stems from studies (e.g., Kagan \& Berkun, 1954) which have reported that rats will barpress for the reinforcement of running in an activity wheel.

If the hypothesis that an organism's behavior is directed toward controlling its environment is tenable, it could be reasoned that subjects "work," when given the choice between working and freeloading, in order to exercise greater control over their environment. That is, the subjects can concurrently manipulate (control) the environment and reduce their hunger; freeloading, on the other hani, simply reduces the animal's hunger. The control hypothesis was explored in the present investigation by providing an open-field environment with the following work freeload choices simultaneously available: (1) a free-food dish, (2) a nonfunctional bar with no adjacent free food, (3) a nonfunctional bar with adjacent free food, and (4) a functional bar with contingent food presentations.

\section{METHOD}

\section{Subjects}

Eight experimentally naive albino rats were used as subjects. The animals, approximately 180 days old at the beginning of the study, were housed in individual cages with water available ad lib throughout the experiment.

\section{Apparatus}

A cylindrical activity chamber, $60 \mathrm{~cm}$ in diam with a 42-cm-high aluminum wall painted flat black on the inside, was used. The wire-mesh floor was sectioned into quadrants; and round aluminum bars, $1 \mathrm{~cm}$ in diam, $4 \mathrm{~cm}$ in length, and located $6.5 \mathrm{~cm}$ from the wall, were mounted through the floor in three of the quadrants. Circular hard plastic dishes, $5 \mathrm{~cm}$ in diam and $1.6 \mathrm{~cm}$ deep, were attached to the floor $4 \mathrm{~cm}$ from the wall. The quadrants contained, respectively: (1) a functional bar and food dish with pellet delivery dispensed on a continuous reinforcement schedule (CRF), (2) a nonfunctional bar and food dish which contained no free food during training (free food/bar, or FFB), (3) a nonfunctional bar (bar only, or BO), and (4) a foodcup which contained no free food during training (free food 


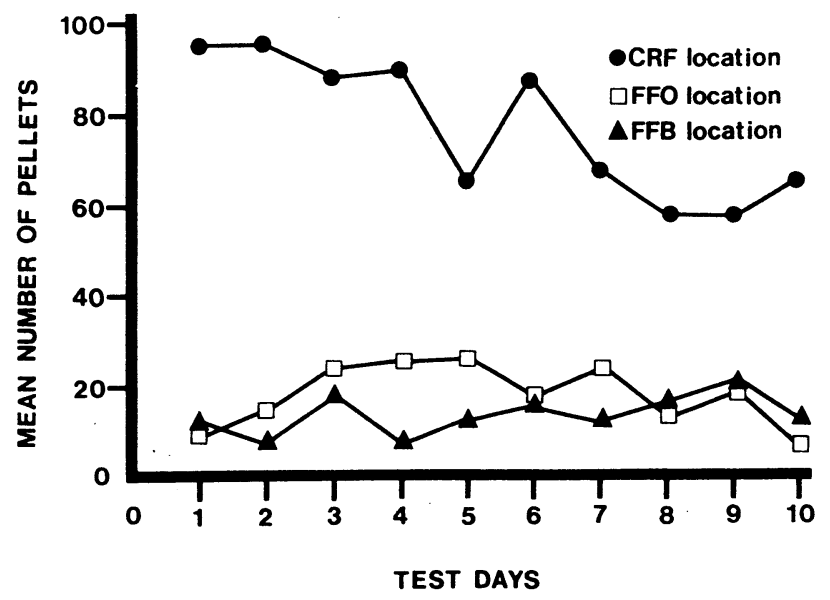

Figure 1. Mean number of pellets obtained at the CRF, FFO, and FFB locations.

only, or FFO). Any barpress produced an audible click by a microswitch and activated one of three counters. Responses on the CRF bar activated a pellet dispenser located outside the apparatus and deposited a 45-mg Noyes food pellet in the dish by the bar. Four sets of photocells were arranged so that when a subject was near any food or bar location (within $2 \mathrm{~cm}$ ) the interruption of two infrared light beams crossing each area activated one of four timers. When an animal left an area, the beams were unbroken, and the equipment would cease timing. Separate counters recorded number of minutes spent at each location and number of responses on each of the bars. All programming equipment was housed in a separate room. Diffuse overhead lighting was provided, and white noise was presented from a speaker located above the chamber.

\section{Procedure}

Following 2 weeks on a 23 -h food deprivation schedule, the rats were placed inside the experimental chamber for 30 min of exploration and magazine training on 2 successive da!s. Four days of barpress training were then conducted at the CRF location with one 30 -min session per day. The free-food dishes in the FFO and FFB locitions were present but empty throughout these four sessions to control for any novelty effect. Likewise, the bars were present in the BO and FFB locations. Each rat was allowed $30-\mathrm{min}$ access to lab chow in its home cage following these and all additional sessions. Following the four shaping sessions, the animals were given 20-min daily barpress-training sessions for 25 days. Finally, 10 days of choice testing were conducted with each of the two free-food dishes filled with 150 pellets and all other conditions remaining the same. Throughout the experiment, the following measures were recorded for each session: (1) number of minutes spent at each of the four locations, (2) number of responses on each of the bars, and (3) number of pellets obtained at each of the food locations (electromechanically for the CRF area and by counting number of pellets remaining at each free-food locatiun after each session).

\section{RESULTS AND DISCUSSION}

At the conclusion of the training sessions, the CRF response rates of all subjects had stabilized at 180-185 barpresses per session. The response rate on the BO and FFB bars was essentially zero during training with no subject pressing either bar more than four times per session. When free food was introduced on the choice-test days, the subjects continued to receive most of their food via CRF barpressing. The percentage of consumed pellets that were obtained by barpressing ranged from 41.6 to 92.4 of the total number of pellets for each animal. Seven subjects recieved more than $50.0 \%$ of the pellets consumed by pressing the CRF bar. The mean number of pellets consumed per subject on each choice day at each location is presented in Figure 1. The number of pellets consumed at the CRF location was markedly higher than the number consumed at either the FFO or FFB locations. The number of pellets consumed at the latter two locations did not appreciably differ from each other. Barpressing preference paralleled the pellet consumption data. The subjects pressed the bar very few times at the FFB and BO locations during the choice sessions (range from zero to five responses per session). There was no difference in the number of barpresses at the FFB and BO locations, and the number of responses remained at essentially the same level observed during training. The average number of responses per choice session made at the CRF location remained high (as indicated by a high level of CRF pellet consumption) but did decrease considerably from the response rate noted for the training sessions.

Figure 2 shows the mean number of minutes all animals spent at each of the four locations during the 10 choice-test days. On test days, the animals would generally spend approximately the first $2 \mathrm{~min}$ of the session eating from one of the free dishes and would press the CRF bar for most of the remainder of the session, except for brief intermittent returns to the FFB and FFO locations. However, one subject immediately began pressing at the CRF bar when placed in the chamber and spent little time at the other locations. It was further noted that, on days when subjects did consume a majority of their food from FFO and/or FFB locations, they usually continued to spend most of the session time at the CRF location.

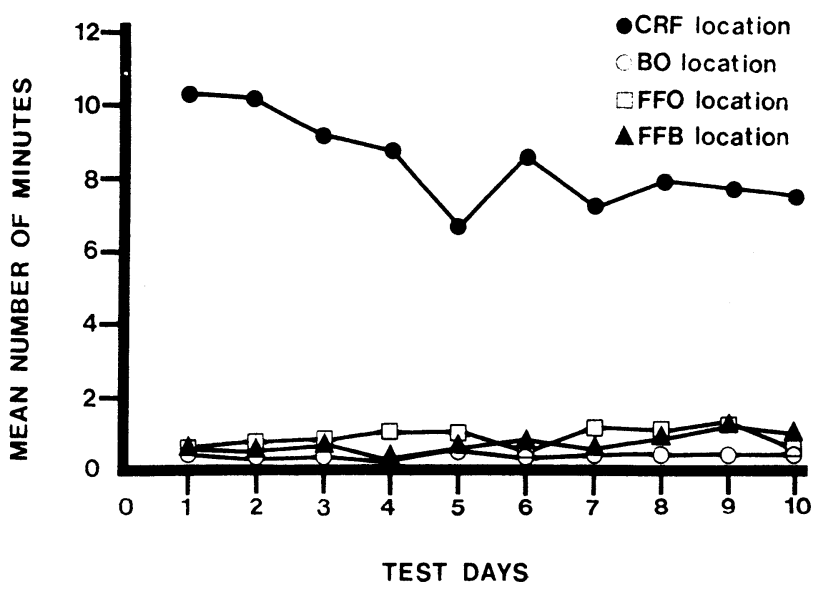

Figure 2. Mean amount of time spent at the CRF, FFB, FFO, and $\mathrm{BO}$ locations. 
The present findings indicate that rats will continue to barpress for the majority of their food in the presence of other food-getting or manipulation alternatives. This result is consistent with the findings of others (e.g., Jensen, 1963) and at odds with the traditional Hullian principle of least effort. Simple reinforcement explanations are taxed to account for subjects working the majority of the time for most of their food. It could be hypothesized that secondary reinforcers may account for the behavior; that is, the motor activity of barpressing or auditory feedback from the microswitch could be considered secondarily reinforcing and, therefore, a possible explanation for the work preference. However, the present study shows that, although (1) the same auditory feedback was produced, and (2) the same motor activity could be exerted at two other bars, the subjects continued to respond for their food. The visual and auditory properties of a single pellet dropping into a dish could also be considered secondary reinforcers. However, Singh (1970) eliminated this possibility by dispensing free food one pellet at a time, and the subjects still preferred to work. Furthermore, Jensen's (1963) contention that barpressing has some "intrinsic appeal" for rats is also untenable since the subjects in the present experiment pressed very little at the FFB and BO locations. The present results indicate that, in choice situations, the activity of barpressing is maintained only when it is followed by a primary reinforcer. These results support White's (1959) contention that animals are motivated to actively manipulate their environment. Support for such a concept was offered by Kavanau (1967) who reported that deer mice repeatedly tore down and rebuilt nests provided for them and learned to operantly respond to control many environmental events (e.g., food and water availability, activity wheel access, and light intensity in their cages) rather than passively receiving these stimuli. The Protestant ethic effect seems best explained at this time by White's (1959) hypothesis. When rats are provided with a choice between free food and response-contingent food, they prefer to control the process of receiving food by operantly responding (on a nonstringent schedule) to the environment.

\section{REFERENCES}

Alferink, L, A. Crossman, E, K \& Cheney, C. D. Control of responding by a conditioned reinforcer in the presence of free food. Animal Learning \& Behavior, 1973, 1, 38-40.

Carder, B., \& Berkowitz, K. Preference for earned food in relation to free food. Science, $1970,167,1273-1274$.

Jensen, G. D. Preferences for barpressing over "freeloading" as a function of number of rewarded presses. Journal of Experimental Psy chology, 1963, 65, 451-454.

Kagan, J., \& Berkun, M. The reward value of running activity. Journal of Comparative and Phy siological Psychology, 1954, 47, 59-64.

Kavanau, J. L. Behavior of captive white footed mice. Science, $1967,55,1523-1639$.

Neuringer, A. J. Many responses per food reward with free food present. Science, $1970,169,503-504$.

Singh, D. Preference for barpressing to obtain reward over freeloading in rats and children. Journal of Comparative and Phy siological Psy chology, 1970, 73, 320-327.

Singh, D., \& Query, W. T. Preference for work over "freeloading" in children. Psychonomic Science, 1971, 24, 77-79.

Tarte, R. D., \& Snyder, R. L. Barpressing in the presence of free food as a function of food deprivation. Psy chonomic Science, $1972,26,169-170$.

Taylor, C. T. A limitation of the contrafreeloading phenomenon. Psychonomic Science, 1972, 29, 173-174.

White, $R$. W. Motivation reconsidered: The concept of competence. Psy chological Review, 1959, 66, 297-333.

(Received for publication April 17, 1975.) 